\title{
Werkhervatting van zieke en niet-zieke werklozen
}

\author{
R. Steenbeek, K. Jettinghoff
}

Na een jarenlange stijging zien we nu dat het aantal werklozen weer daalt. Tussen 200I en 2004 nam het aantal (lopende) WW-uitkeringen toe van I65.700 naar 321.700. Sinds 2005 daalde het aantal (lopende) WW-uitkeringen naar 306.700 in 2005 en 249.200 in 2006. Ook het aantal nieuwe WW-uitkeringen daalde sinds 2005. Deze daling is het gevolg van de verbeterde economische omstandigheden en een kortere looptijd van WW-uitkeringen. ${ }^{\text {I }}$ Door de daling in het aantal werklozen en door de vergrijzing en ontgroening dreigt een krapte op de arbeidsmarkt te ontstaan. Het is dan ook van groot belang om de arbeidsparticipatie van werklozen verder te verhogen. Dit is niet alleen in het belang van de maatschappij, maar ook in het belang van de werklozen. Naast het verschaffen van inkomen en financiële onafhankelijkheid heeft betaald werk verschillende positieve aspecten.

\section{HET BELANG VAN WERK}

Het hebben van werk heeft een aantal belangrijke functies in het leven van personen. Het biedt structuur, personen ontlenen er hun sociale status en identiteit aan, het draagt bij aan een gevoel van maatschappelijke betrokkenheid, het biedt mogelijkheden voor persoonlijke ontplooiing en het is een belangrijke bron van sociale contacten. $^{2-4}$ Wanneer een persoon werkloos wordt, vallen deze zingevende en structurerende functies van werk weg.

Werk is eveneens belangrijk voor de gezondheid en het welzijn. Dit blijkt onder meer uit onderzoek naar de gevolgen van werkhervatting vanuit werkloosheid. Werklozen die hervatten in werk, ervaren minder angst en stress, ${ }^{5,6}$ hebben minder kans op depressieve klachten ${ }^{7}$ en ervaren een betere psychische en lichamelijke gezondheid. ${ }^{\text {8.10 }}$ Hier staat tegenover dat het niet hebben van werk negatieve effecten heeft. Echtparen van wie de man is ontslagen, rapporteren bijvoorbeeld grotere financiële zorgen en een ongunstigere financiële situatie dan echtparen van wie de man werkt. ${ }^{\text {II }}$ Werklozen blijken ook minder tevreden te zijn met hun leven (life satisfaction) en met hun huwelijk en familie. ${ }^{\text {ro }}$ Tevens blijkt uit verschillende onderzoeken dat werklozen meer gezondheidsklachten ervaren dan werkenden. . $0,12-14$ Verder blijkt dat werklozen vaker roken en minder sporten. ${ }^{13}$

\section{SAMENVATTING}

Doel van dit onderzoek is het krijgen van inzicht in belemmerende en bevorderende factoren ten aanzien van gezondheidsherstel en terugkeer naar werk van werklozen. Het betreft een longitudinaal vragenlijstonderzoek van twee metingen met een jaar ertussen onder 870 werklozen uit de WW- en ZW-bestanden van oktober 2005. Uit dit onderzoek blijkt dat ziek zijn op de eerste meting de belangrijkste voorspeller vormt voor (nog steeds) ziek zijn een jaar later. Voor werkhervatting blijkt de belangrijkste belemmerende factor een hogere leeftijd te zijn. Van de werkloze 55-plussers in onze dwarsdoorsnede van de WW- en ZW-bestanden is slechts 3,6\% na een jaar weer aan het werk.

Herstel van zieke werklozen kan bevorderd worden door vroegtijdig contact met de zieke werkloze, meer aandacht voor de gezondheidsproblemen, stimuleren van zelfvertrouwen en een positieve mening over werk, en het leveren van meer 'maatwerk' door UWV, CWI en re-integratiebedrijven. Om werkhervatting te bevorderen is het van belang ervoor te zorgen dat het aannemen van oudere werklozen wordt gestimuleerd en dat vraag en aanbod op de arbeidsmarkt goed op elkaar worden afgestemd. De lage kans op werk van ouderen staat op gespannen voet met het streven van het kabinet tot verhoging van de arbeidsparticipatie.

\section{FACTOREN DIE WERKHERVATTING BEÏNVLOEDEN}

Om de arbeidsparticipatie van werklozen te bevorderen is het van belang om inzicht te hebben in factoren die werkhervatting van werklozen bevorderen dan wel belemmeren. Hierover is reeds het een en ander bekend.

Bepaalde groepen werklozen ondervinden meer problemen bij terugkeer naar werk. Dit betreft onder meer vrouwen en (ex-)arbeidsongeschikten, ${ }^{15}$ ouderen, ${ }^{15,16}$ allochtonen, ${ }^{5,17}$ lager opgeleiden en personen met een uitkeringsduur langer dan één jaar. ${ }^{16}$ Verder zijn er aanwijzingen dat de aanwezigheid van thuiswonende kinderen werkhervatting stimuleert. ${ }^{6}$

Ook de eigen wensen, attituden en inspanningen ten aanzien van werk zijn van invloed op werkhervatting. Werklozen met een hoog gewenst loon en werklozen die een deeltijdbaan wensen, vinden minder snel een baan. Werklozen die meer sociale contacten onderhouden en die werk belangrijk vinden, zijn daarentegen kansrijker op terugkeer naar werk. ${ }^{\text {I5 }}$ Actief zoekgedrag blijkt eveneens een belangrijke voorwaarde voor werkhervatting. ${ }^{15,16}$ Niet alle zoekkanalen voor het vin-
WERKLOZEN, GEZONDHEIDS HERSTEL, WERKHERVATTING, OUDEREN 
den van een baan zijn echter even effectief. Het ingeschreven staan bij een uitzendbureau (zoekkanaal) werkt duurverkortend. ${ }^{\text {is }}$ Tevens blijkt dat werklozen die contact hebben met het arbeidsbureau, vaker solliciteren en een iets hogere kans op succes hebben bij sollicitatie. ${ }^{\mathrm{I}}$

De sector waarin men werkzaam was en de aard van het dienstverband voordat men werkloos werd, spelen ook een rol bij werkhervatting. Werklozen uit de dienstensector hebben een langere werkloosheidsduur. ${ }^{15}$ Werklozen uit uitzendwerk of met een oproepbaan hervatten werk sneller dan werklozen uit een vast dienstverband. Verder is het gegeven dat vangnetters (o.a. uitzendkrachten en werklozen) geen vaste werkgever hebben bij wie zij kunnen hervatten in werk, een belemmerende factor voor werkhervatting van deze specifieke groep. ${ }^{\mathrm{I}}$

Gezondheid is ook van invloed op werkhervatting. Zieke werklozen hebben minder kans op werkhervatting dan gezonde werklozen.' Verder is gebleken dat geestelijke gezondheidsklachten in het algemeen ${ }^{\text {19 }}$ en psychosomatische klachten in het bijzonder ${ }^{20}$ werkhervatting belemmeren.

\section{DOELSTELLING EN ONDERZOEKS- VRAAG}

Uit het bovenstaande blijkt dat veel factoren de werkhervatting van werklozen beïnvloeden. In dit onderzoek kijken we naar de relatieve invloed hiervan, zodat beleid ontwikkeld kan worden dat gericht is op de belangrijkste beïnvloedbare factoren. Aangezien gezondheid een belangrijke rol speelt bij de mogelijkheden tot werkhervatting, kijken we bij de resultaten eerst naar factoren die 'niet ziek zijn' beïnvloeden. Hierna presenteren we de resultaten voor werkhervatting. De onderzoeksvraag die in dit artikel centraal staat, luidt:

I Ziek zijn op de eerste meting vormt de belangrijkste voorspellende factor voor (nog steeds) ziek zijn een jaar later.

I Ouderen lijken kansloos op de arbeidsmarkt. Slechts 3,6\% van de werkloze 55-plussers in onze dwarsdoorsnede van de WW- en ZWbestanden is na een jaar weer aan het werk.

I Gezondheidsherstel kan bevorderd worden door vroegtijdig contact met de zieke werkloze, meer aandacht voor de gezondheidsproblemen, stimuleren van zelfvertrouwen en een positieve mening over werk, en het leveren van meer 'maatwerk' door UWV, CWI en reintegratiebedrijven.

I Werkhervatting kan bevorderd worden door het aannemen van oudere werklozen te stimuleren en vraag en aanbod op de arbeidsmarkt goed op elkaar af te stemmen.
I Wat zijn de belangrijkste belemmerende en bevorderende factoren ten aanzien van gezondheidsherstel en terugkeer naar werk van werklozen?

\section{METHODE}

Onderzoeksdesign en steekproef

Om deze onderzoeksvraag te beantwoorden hebben we een longitudinaal vragenlijstonderzoek uitgevoerd onder werklozen. Hiertoe heeft UWV een steekproef getrokken van 4000 personen uit het WW-bestand en 5000 personen uit het ZWbestand die in oktober 2005 bij UWV geregistreerd stonden als werkloos. De steekproef is aselect getrokken en representatief voor leeftijd, geslacht, WW-duur (WW-bestand) en verzuimduur (ZW-bestand). De resultaten zijn gewogen voor het aandeel WW en ZW in de UWV-populatie; ZW'ers maken ongeveer $9 \%$ van het totaal uit.

De eerste vragenlijst is verstuurd in januari 2006 aan 9000 personen, van wie 3048 personen de vragenlijst hebben ingevuld en teruggestuurd (respons 33,8\%). De tweede vragenlijst is verstuurd in februari 2007, alleen aan personen die (I) deel hadden genomen aan de eerste meting, (2) bereid waren mee te werken aan een tweede meting, en (3) toestemming hadden gegeven om de vragenlijst te koppelen aan gegevens van UWV. Dit betrof I637 personen van wie 879 de vragenlijst hebben ingevuld en teruggestuurd (respons 53,7\%).

De analyses in dit artikel zijn uitgevoerd op 870 respondenten die zowel aan de eerste als aan de tweede meting hebben meegewerkt en van wie gegevens van UWV bekend waren over hun eindsituatie (gegevens over WW en ZW). Deze onderzoeksgroep is over het algemeen wat ouder dan de UWV-populatie. Van deze 870 respondenten is $43 \%$ vrouw en de gemiddelde leeftijd bedraagt 49 jaar $(\mathrm{SD}=9)$.

\section{Onderzoeksvariabelen}

De vragenlijst voor de eerste meting bestond onder meer uit vragen over de volgende onderwerpen: persoonsgegevens, kenmerken van de thuissituatie, arbeidsverleden, persoonlijkheid, werkhervatting, ziekte en herstel, inkomsten en gezondheid. De variabelen die in dit onderzoek aan bod komen, staan weergegeven in tabel I. 'Niet ziek' op meting 2 is gedefinieerd als 'geen ZW en niet ziek' op meting 2 . Tabel 2 geeft weer hoeveel ZW'ers en WW'ers van meting I op meting 2 ziek zijn, hersteld, werkloos of hervat in werk. Voor nadere informatie over de vragenlijst zie Steenbeek et al. ${ }^{2 \mathrm{I}}$ 


\section{Analyses}

Om vast te stellen welke kenmerken uit de eerste meting (de onafhankelijke variabelen) van invloed zijn op 'niet ziek zijn' en werkhervatting een jaar later op de tweede meting (de afhankelijke variabelen) zijn gewogen multivariate logistische regressieanalyses uitgevoerd. Voor deze analyses zijn onafhankelijke variabelen geselecteerd die onderling niet te sterk met elkaar samenhangen $(r<0,50)$ en univariaat een redelijke samenhang vertonen met 'niet ziek zijn' dan wel werkhervatting ( $r \geq 0, \mathrm{IO})$. Geslacht, leeftijd, opleiding en 'in de laatste baan werkzaam als uitzendkracht' zijn altijd meegenomen in de regressieanalyses. Voor onafhankelijke variabelen die op basis van deze selectie niet in de analyses zijn opgenomen, verwijzen we naar Steenbeek et al. ${ }^{21}$

\section{RESULTATEN}

\section{'Niet ziek'}

De resultaten van de multivariate logistische regressieanalyses voor de afhankelijke variabele 'niet ziek' zijn samengevat in tabel 3. Vooral ziek zijn op de eerste meting blijkt een sterke belemmering te vormen voor niet ziek zijn een jaar later $(\mathrm{OR}=0,09)$. De kans om na een jaar niet ziek te zijn blijkt ook groter te zijn voor werklozen met een positievere mening over werk $(\mathrm{OR}=$ 2,33 ) en werklozen die 45 jaar of ouder zijn (45-54 jaar: $\mathrm{OR}=2,6 \mathrm{I}$ en $\geq 55$ jaar: $\mathrm{OR}=3,29$ ). Vooral dit laatste is opvallend.

\section{Werkhervatting}

De resultaten van de multivariate logistische regressieanalyses voor de afhankelijke variabele werkhervatting zijn samengevat in tabel 4 . Een hogere leeftijd blijkt de sterkste belemmering te vormen voor werkhervatting. Respondenten van 55 jaar en ouder hebben een aanzienlijk kleinere kans $(\mathrm{OR}=0,04)$ en respondenten in de leeftijd van 45-54 jaar hebben een kleinere kans (OR = 0,45 ) om ten tijde van de tweede meting weer aan het werk te zijn dan respondenten van 44 jaar en jonger. Verder belemmert een langere werkloosheidsduur ( $15-30$ maanden: $\mathrm{OR}=0,60$ en $>30$ maanden: $\mathrm{OR}=0,42$ ) werkhervatting een jaar later. Kenmerken die werkhervatting een jaar later bevorderen, zijn een hoog opleidingsniveau $(\mathrm{OR}=2,3 \mathrm{I})$, een hoog zelfvertrouwen $(\mathrm{OR}=2,25)$, inkomsten uit werk voor 20 uur of meer per week $(\mathrm{OR}=2,06)$ of thuiswonende kinderen $(\mathrm{OR}=\mathrm{I}, 74)$.

\section{Wat denken de werklozen zelf?}

Opvallend veel respondenten hebben gebruikgemaakt van de mogelijkheid om opmerkingen te plaatsen in de vragenlijst (januari 2006). Hieruit

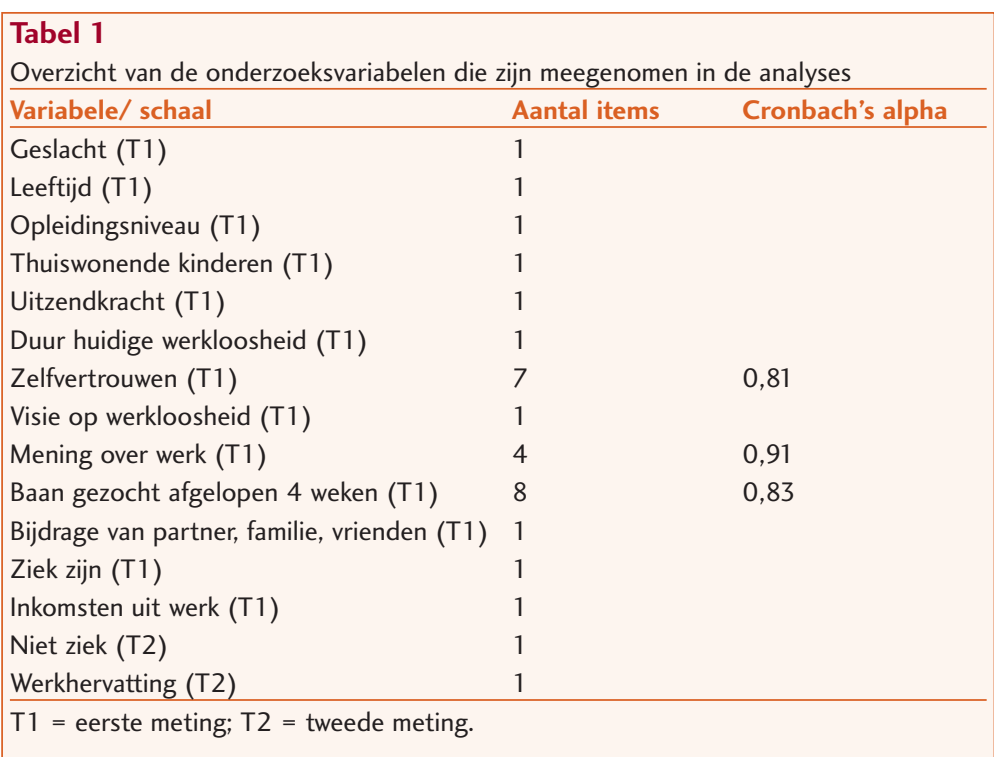

\begin{tabular}{|c|c|c|c|c|}
\hline \multirow[b]{2}{*}{ Meting } & \multicolumn{2}{|c|}{ Meting $1 \mathrm{ZW}$} & \multicolumn{2}{|c|}{ Meting $1 \mathrm{WW}$} \\
\hline & $n$ & $\%$ & $n$ & $\%$ \\
\hline Ziek & 48 & 58,5 & 72 & 9,1 \\
\hline Hersteld & 25 & 30,5 & & 0,0 \\
\hline Werkloos & & 0,0 & 526 & 66,8 \\
\hline Hervat & 9 & 11,0 & 190 & 24,1 \\
\hline Totaal & 82 & 100 & 788 & 100 \\
\hline
\end{tabular}

\begin{tabular}{|c|c|c|}
\hline \multicolumn{3}{|c|}{$\begin{array}{l}\text { Uitkomsten van de multipele logistische regressieanalyse voor de afhankelijke variabele } \\
\text { 'niet ziek' op de tweede meting }(n=774)\end{array}$} \\
\hline \multirow[b]{2}{*}{ Kenmerken op T1 } & \multicolumn{2}{|c|}{ Niet ziek T2 } \\
\hline & $\overline{\mathrm{OR}}$ & $95 \%-\mathrm{BI}$ \\
\hline \multicolumn{3}{|l|}{ Geslacht } \\
\hline man & Ref. & \\
\hline vrouw & 0,90 & $0,54-1,49$ \\
\hline \multicolumn{3}{|l|}{ Leeftijd } \\
\hline 44 jaar en jonger & Ref. & \\
\hline $45-54$ jaar & $2,61^{* * *}$ & $1,46-4,68$ \\
\hline 55 jaar en ouder & $3,29^{* * *}$ & $1,67-6,47$ \\
\hline \multicolumn{3}{|l|}{ Opleidingsniveau } \\
\hline laag (geen/basis/mavo/lbo) & Ref. & \\
\hline middel (havo/vwo/mbo) & 0,85 & $0,50-1,45$ \\
\hline hoog (hbo/wo) & 0,94 & $0,45-1,96$ \\
\hline \multicolumn{3}{|c|}{ In laatste baan werkzaam als uitzendkracht } \\
\hline nee & Ref. & \\
\hline ja & 0,69 & $0,38-1,27$ \\
\hline \multicolumn{3}{|c|}{ Momenteel aantal maanden zonder werk } \\
\hline $0-14$ maanden & Ref. & \\
\hline 15-30 maanden & 0,79 & $0,43-1,46$ \\
\hline 31 maanden of meer & 0,85 & $0,46-1,56$ \\
\hline \multicolumn{3}{|l|}{ Zelfvertrouwen (schaal) } \\
\hline laag (referentie) & Ref. & \\
\hline hoog & 1,06 & $0,65-1,74$ \\
\hline \multicolumn{3}{|l|}{ Mening over werk (schaal) } \\
\hline werk is minder belangrijk & Ref. & \\
\hline werk is (zeer) belangrijk & $2,33^{* *}$ & $1,38-3,94$ \\
\hline \multicolumn{3}{|l|}{ Momenteel ziek } \\
\hline nee & Ref. & \\
\hline ja & $0,09^{* * *}$ & $0,06-0,15$ \\
\hline Cox \& Snell $R^{2}$ & 0,16 & \\
\hline${ }^{* *} p<0,01 ;{ }^{* * *} p<0,001$. & & \\
\hline
\end{tabular}




\begin{tabular}{|c|c|c|}
\hline $\begin{array}{l}\text { Tabel } 4 \\
\text { Uitkomsten van de multipele lo } \\
\text { werkhervatting op de tweede } \mathrm{m}\end{array}$ & sieanalyse & afhankelijke variabele \\
\hline & Werkher & \\
\hline Kenmerken op T1 & OR & $95 \%-B I$ \\
\hline Geslacht & & \\
\hline man & Ref. & \\
\hline vrouw & 0,82 & $0,53-1,28$ \\
\hline Leeftijd & & \\
\hline 44 jaar en jonger & Ref. & \\
\hline $45-54$ jaar & $0,45^{* * *}$ & $0,29-0,71$ \\
\hline 55 jaar en ouder & $0,04^{* * *}$ & $0,01-0,10$ \\
\hline Opleidingsniveau & & \\
\hline laag (geen/basis/mavo/lbo) & Ref. & \\
\hline middel (havo/vwo/mbo) & 0,88 & $0,54-1,44$ \\
\hline hoog (hbo/wo) & $2,31^{* *}$ & $1,35-3,98$ \\
\hline Thuiswonende kinderen & & \\
\hline nee & Ref. & \\
\hline ja & $1,74^{*}$ & $1,13-2,67$ \\
\hline In laatste baan werkzaam als uitz & & \\
\hline nee & Ref. & \\
\hline ja & 0,45 & $0,83-2,54$ \\
\hline Momenteel aantal maanden zond & & \\
\hline 0-14 maanden & Ref. & \\
\hline 15-30 maanden & $0,60^{*}$ & $0,37-0,97$ \\
\hline 31 maanden of meer & $0,42^{* *}$ & $0,23-0,75$ \\
\hline Visie op werkloosheid & & \\
\hline (helemaal) niet vervelend & Ref. & \\
\hline weet niet & 1,25 & $0,71-2,22$ \\
\hline (heel) erg vervelend & 1,35 & $0,80-2,30$ \\
\hline Zelfvertrouwen (schaal) & & \\
\hline laag & Ref. & \\
\hline hoog & $2,25^{* * *}$ & $1,44-3,50$ \\
\hline Momenteel ziek & & \\
\hline nee & Ref. & \\
\hline ja & 0,77 & $0,43-1,35$ \\
\hline Mening over werk (schaal) & & \\
\hline werk is minder belangrijk & Ref. & \\
\hline werk is (zeer) belangrijk & 1,36 & $0,88-2,10$ \\
\hline Hoe naar een baan gezocht afgelc & & \\
\hline 4 weken & & \\
\hline $0-5$ activiteiten ondernomen & Ref. & \\
\hline $6-8$ activiteiten ondernomen & 1,41 & $0,91-2,19$ \\
\hline $\begin{array}{l}\text { Positieve bijdrage aan herstel en/c } \\
\text { terugkeer naar werk van partner, } f\end{array}$ & & \\
\hline of vrienden & & \\
\hline nee & Ref. & \\
\hline ja & 1,28 & $0,76-2,17$ \\
\hline Heeft voor 20 of meer uur per we & & \\
\hline inkomsten uit werk & & \\
\hline nee & Ref. & \\
\hline ja & $2,06^{* *}$ & $1,20-3,56$ \\
\hline Cox \& Snell $R^{2}$ & 0,27 & \\
\hline
\end{tabular}

blijkt dat er veel frustraties bestaan ten aanzien van de begeleiding bij gezondheidsherstel en/of terugkeer naar werk. Werklozen die aangeven hier ontevreden over te zijn, hebben vooral kritiek op de werkwijze van en de benadering door UWV, CWI en re-integratiebedrijven. De tendens is dat de werkwijze van deze instanties te veel is gericht op regels en procedures en dat de benade- ring van deze instanties te weinig gericht is op de persoon waar het om gaat. Zieke werklozen geven ook nog als aanvullende kritiek dat UWV, CWI en re-integratiebedrijven te veel oog hebben voor de werkhervatting en te weinig aandacht hebben voor de gezondheidssituatie van de cliënt.

Verder blijkt dat veel werklozen de weg kwijtraken in de wet- en regelgeving. Cliënten blijken ook niet goed onderscheid te kunnen maken tussen de functies van UWV, CWI en re-integratiebedrijven.

\section{DISCUSSIE}

'Niet ziek'

Het onderwerp 'ziekte' bij werklozen verdient speciale aandacht. Aan de ene kant bevordert een slechte gezondheid werkloosheid. Aan de andere kant verslechtert de gezondheid ook na het wegvallen van werk. Uit dit onderzoek blijkt dat ziek zijn op een bepaald moment de belangrijkste voorspeller vormt voor ziek zijn een jaar later, oftewel ziek zijn betekent vaak ziek blijven of opnieuw ziek worden. Een uitzondering hierop vormen zieke werklozen vanaf 45 jaar. Zij herstellen ruim tweemaal zo vaak als jongeren. Een mogelijke verklaring hiervoor is het healthy worker effect; vooral gezonde oudere werknemers blijven doorwerken tot hun 65e levensjaar. Minder gezonde oudere werknemers hebben intussen de arbeidsmarkt al verlaten (bijv. via prepensioen). Bij zieke werklozen heeft men het vaak over 'ziektewinst'. Sommige werklozen onderkennen inderdaad dat het voordelen heeft om ziek te zijn. Dit verlengt de uitkeringsduur en de netto hoogte van de uitkering vanwege de arbeidskorting. Bij het vragen naar de belangrijkste reden van hun ziekmelding noemen werklozen echter gezondheidsklachten. Uit de resultaten van dit onderzoek blijkt inderdaad dat ziek zijn wordt verklaard door ziekte en/of gezondheidsklachten en niet primair door ziektewinst. Echter, ziektewinst kan mogelijk een rol spelen bij jongere werklozen, omdat deze groep tegen de verwachting in minder vaak herstelt dan oudere werklozen.

Hoe kan gezondheidsherstel bij zieke werklozen bevorderd worden? Uit dit onderzoek blijkt dat vroegtijdig contact met de zieke werkloze, aandacht voor de gezondheidsproblemen, stimuleren van zelfvertrouwen en stimuleren van een positieve mening over werk bijdragen aan herstel. Ook het leveren van meer 'maatwerk' door UWV, CWI en re-integratiebedrijven kan bijdragen aan het gezondheidsherstel van zieke werk- 
lozen: meer aandacht voor de individuele situatie van de cliënt, meer aandacht voor diens gezondheid en meer aandacht voor de bijdrage van de curatieve sector. Uit het onderzoek blijkt dat de cliënt zich niet serieus genomen voelt en dan dus de nadruk legt op zijn ziekte. Het idee is dat wanneer de cliënt zich wel serieus genomen voelt, hij de aandacht van gezondheidsherstel richting werkhervatting zal verleggen. Natuurlijk geldt voor een deel van de zieke werklozen dat zij meer kunnen dan ze denken en dat ze meer mogelijkheden hebben dan ze zelf onderkennen. Echter, er zijn erg veel verschillende partijen betrokken bij de begeleiding van zieke werklozen en er lijkt geen probleemeigenaar te zijn.

Verder blijkt uit ander onderzoek dat onvolledige informatie over rechten en handelingsmogelijkheden (in dit geval ten aanzien van de bedrijfsarts) leidt tot verkeerde verwachtingen en teleurstellingen en tot een negatief oordeel over de arts. ${ }^{22}$ Het is dan ook aan te bevelen om werklozen beter voor te lichten en duidelijke en heldere informatie te verstrekken over hun rechten en plichten en over de verschillende rollen van de betrokken partijen en personen, liefst vanaf de eerste ziektedag. Dan weet de (zieke) werkloze vanaf het begin wat hij of zij van wie kan verwachten, wat hij zelf moet doen en welke mogelijkheden hij heeft. Door deze empowerment van cliënten kunnen zij beter gebruikmaken van hun inspraakmogelijkheden bij de keuze van een reintegratietraject.

\section{Werkhervatting}

Voor jongere werklozen is het van belang dat zij niet ziek worden of blijven, dat zij gestimuleerd worden om actief naar werk te zoeken en dat hun zelfvertrouwen wordt verhoogd, bijvoorbeeld door middel van scholing. Het accepteren van een deeltijdbaan loont ook; dit verhoogt de kans om later volledig te hervatten. Ouderen blijken erg moeilijk aan werk te komen, terwijl deze mensen juist hard nodig zullen zijn gezien de vergrijzing en de veranderingen op de arbeidsmarkt. Vorig jaar is een onderzoek afgerond naar re-integratie bij oudere werkzoekenden met behulp van good practices. ${ }^{23}$ Hieruit blijkt dat er nog weinig ervaring is met de systematische en methodisch onderbouwde re-integratie van oudere werkzoekenden en dat een verdere stimulans noodzakelijk is. De conclusies zijn in overeenstemming met de bevindingen van ons onderzoek.

De werkhervatting van ouderen kan bevorderd worden door ervoor te zorgen dat het aannemen van oudere werklozen wordt gestimuleerd (ver- betering beeldvorming) en dat vraag en aanbod op de arbeidsmarkt goed op elkaar worden afgestemd. $^{2}$

UWV heeft ondertussen verschillende initiatieven genomen om maatwerk te bevorderen en de communicatie te verbeteren. Deze maatregelen waren nog niet van toepassing op de populatie uit dit onderzoek. Het is volgens de onderzoekers wel een punt van aandacht om ook deze 'oude' populatie bij de nieuwe maatregelen te betrekken.

\section{LITERATUUR}

I. UWV. Feiten en cijfers: Statistisch zakboekje 2006 Amsterdam: UWV, 2007.

2. Merens-Riedstra H. Leven zonder werk. Een sociaalwetenschappelijk onderzoek naar arbeidsongeschiktheid [proefschrift]. Aachen: Rijksuniversiteit Limburg, I98I.

3. Jahoda M. Employment and unemployment: A socialpsychological analysis. Cambridge: Cambridge University Press, I982.

4. Hoff S, Jehoel-Gijsbers G. Een bestaan zonder baan. Rijswijk/Den Haag: Sociaal en Cultureel Planbureau/ Elsevier bedrijfsinformatie, I998.

5. Kessler RC, Turner JB, House JS. Unemployment, reemployment and emotional functioning in a community sample. Am Sociol Rev I 989; 54: 648-657.

6. Leana CR, Feldman DC. Finding new jobs after a plant closing: antecedents and outcomes of the occurrence and quality of reemployment. Human Relat I995; 48: I38I-I40I.

7. Claussen B, Bjorndal A, Hjort PF. Health and reemployment in a two year follow up of long term unemployed. J Epidemiol Commun Health I993; 47: I4-I8.

8. Warr P, Jackson P. Factors influencing the psychological impact of prolonged unemployment and of reemployment. Psychol Med I985; I5: 795-807.

9. Wanberg CR. A longitudinal study of the effects of unemployment and quality of reemployment. J Vocational Behav I995; 46: 40-54.

Io. McKee-Ryan FM, Song Z, Wanberg CR, et al. Psychological and physical well-being during unemployment: A meta-analytic study. J Appl Psychol 2005; 90: $53-76$.

I I. Aubry T, Tefft B, Kingsbury N. Behavioral and psychological consequences of unemployment in blue-collar couples. J Commun Psychol i990; I8: 99-I09.

I 2. Lindert H van, Droomers M, Westert GP. Tweede nationale studie naar ziekten en verrichtingen in de huisartspraktijk. Een kwestie van verschil: verschillen in zelfgerapporteerde leefstijl, gezondheid en zorggebruik. Utrecht/Bilthoven: NIVEL/RIVM, 2004

I3. Ybema JF, Evers M. Profiel Arbeid en Gezondheid 2005. Hoofddorp: TNO Kwaliteit van Leven, 2005.

I4. Jin RL, Shah CP, Svoboda TJ. The impact of unemployment on health: a review of the evidence. Can Med Assoc J I995; I 53: 529-540.

I5. Zwinkels WS, Besseling JJM. Werkhervatting van de cliënt in de WW. Den Haag: VUGA Uitgeverijen, I997.

r6. Sociaal en Cultureel Planbureau. De uitkering van de baan. Re-integratie van uitkeringsontvangers: ontwikkelingen in de periode I992-2002. Den Haag: Sociaal Cultureel Planbureau, 2003.

I7. Vinokur AD, Schul Y, Vuori J, et al. Two years after a job loss: Long-term impact of the JOBS program on reemployment and mental health. J Occup Health Psychol 2000; 5: 32-47. 
I8. Ybema JF, Lagerveld S, Berg R van den. Werking Wet verbetering poortwachter onder vangnetgevallen. Hoofddorp: TNO Arbeid, 2004.

I9. Laudet AB, Magura S, Vogel HS, Knight EL. Interest in and obstacles to pursuing work among unemployed dually diagnosed individuals. Substance-Use-andMisuse, 2002, 37: I45-I70.

20. Taris TW. Unemployment and mental health: a longitudinal perspective. Human Sciences 2002; 9: 43-57.

2I. Steenbeek R, Jettinghoff K, Sonneveld HM, Heuvel FMM van den. Gezondheidsherstel en werkhervatting van zieke en niet-zieke werklozen. TNO rapport, Hoofddorp: TNO, 2007.

22. Steenbeek R, Heuvel FMM van den, Buijs PC. Werknemers weten te weinig over hun rechten en handelingsmogelijkheden in relatie tot de bedrijfsarts. Tijdschr Bedrijfs Verzekeringsgeneeskd 2006; I4: 306-3II.

23. Bosselaar H, Berg M van den, Hoedt M den. Re-integratie van oudere werkzoekenden. Lessen uit de eerste good practices. Den Haag, ministerie van SZW, 2006.
Belangenconflicten geen gemeld

DANKWOORD

Het onderzoek is gefinancierd door middel van een subsidie van UWV. Tevens bedanken we alle respondenten.

\section{PERSONALIA}

Dr. Romy Steenbeek en drs. Karin Jettinghoff werken als onderzoeker bij TNO Kwaliteit van Leven I Arbeid te Hoofddorp.

\section{CORRESPONDENTIEADRES}

Dr. R. Steenbeek, TNO Arbeid, Postbus 7I8, 2I30 AS Hoofddorp.

E-mail: romy.steenbeek@tno.nl.

\section{Kwaliteit}

Laatst hadden ze in een bedrijf waar ik veel kom, een verhandeling over het inkopen van bedrijfsgezondheidszorg (BGZ). Het zal wel eens aanbesteed moeten worden in de toekomst. Wat betekent dat? De goedkoopste aanbieder van BGZ krijgt de klant? Gaat het inderdaad om de prijs? Wat zijn we waard? Kiezen ze voor kwaliteit? Hoe meet je dat? Ik merk wel eens dat we gebruikmaken van 'performance indicatoren', is dat kwaliteit?

In de NRC las ik een mooi artikel over het onderwijs, waar het gaat om het halen van een diploma. De manager denkt vervolgens: veel leerlingen (omzet) en veel diploma's (output), dan doe ik het goed. Dan ga ik het proberen met zo weinig mogelijk middelen. Laat de leerlingen maar vooral veel zelf doen. Dit is al jaren aan de gang en we zien dat de inhoud van het diploma aan inflatie onderhevig is. Dat hindert niet, het gaat immers om het behalen van dat diploma.

Zo zie ik ook ontwikkelingen in de BGZ: als de probleemanalyse maar op tijd is. Een handige performance indicator. Maak er een dik pak papier van, dan kun je er ook nog een knappe prijs voor vragen. De argeloze klant wordt massaal wijsgemaakt dat dit goede $B G Z$ is. Poortwachter als melkkoe. Jaarlijks de gezondheidscheck is ook goed te verkopen. Zo krijg je als klant aardig wat producten en de prijs is goed onderhandelbaar. Goedkoop personeel kun je hiervoor inzetten bijvoorbeeld. Is dit de trend in arbodiensten?

Kunnen we het tij keren? Kunnen we laten zien dat onze geleverde zorg en diensten inhoudelijk van toegevoegde waarde zijn? Laten we werk maken van onderzoek naar de kwaliteit van de BGZ. Overigens begint dat met nauwkeurig omschrijven wat we onder kwaliteit verstaan. Doelmatig en doelgericht lijken me wel aardige uitgangspunten.

Bas Sorgdrager 